\title{
CONSTRUCTION MATERIALS AND CONSTRUCTION MARKET DYNAMICS IN GEORGIA
}

\author{
Malkhaz Sulashvili, Associate Professor of Georgian Technical University, Tbilisi, Georgia \\ Neparidze Irine, PhD student of Georgian Technical University, Tbilisi, Georgia \\ Bitchiko Giorgadze, MBA student of Georgian Technical University, Tbilisi, Georgia
}

\section{DOI: https://doi.org/10.31435/rsglobal_conf/25062021/7606}

\begin{abstract}
Production and consumption of construction products is a determinant of significant economic activity globally, these products are used in construction, which is intended for various economic, commercial, pruduction or other purposes, in addition to it is the basis for any kind of infrastructure, transport sector, production facilities or administrative facilities. It is the buildings or other auxiliary infrastructure that enable people to fully engage in their daily activities and live a civil life. The paper includes an in-depth sectoral analysis of the construction sector and the production of building materials in the field of distribution, a study of key trends in both the global and local markets, existing sector regulations and assessments of its development potential based on research by local experts.
\end{abstract}

Keywords: construction materials, construction market, distribution, local experts, regulation.

Introduction. It will be important to emphasize from the very beginning that when talking about the construction market analysis in Georgia, we should consider not only the construction products sector but also the construction industry, as it determines the demand for this material and Directly affects the sale or production of construction products. The issue of production and sale of construction materials is essential and important for global and state economies. As we know this is an important element of economic activity in any country, on the one hand, it attracts foreign direct investment in the country, on the other hand, it lays the foundation for the infrastructure which is necessary for the normal functioning of economic or physical entities. Everything around people created by human hands in their living, working or recreational environment is done by the efforts of the construction sector. For its part, the construction sector is definitely dependent on construction materials, as an important factor in production. Thus, the study of the construction materials market is as relevant as the construction sector itself.

Basic text. The aim of this paper is to find out how much the construction products market has the potential for development and growth in Georgia, So in the construction products market, to study the dynamics of the construction market development, the current situation and prospects in Georgia, to get acquainted with the main indicators, statistics and indicators of sector development or delays, as well as to study the legal environment and its potential impact on the development of the building materials market.

Objectives:

1) To find out what are the global construction and construction market development statistics.

2) What factors influence it?

3) What are the development trends and peculiarities of the field?

In order to process the main research issues in Georgia, as well as to obtain the research results, it is necessary to select the appropriate research methodology. Given the specific of the topic we used quantitative and qualitative research methods. When working on the thesis- we relied on the methods of data collection, grouping comparsion, analysis, systemic approach, statistical analysis, induction and deduction, which were used in the study and research of specific issues.

Georgia is distinguished by high activity and intensity of the construction sector, the main part of which comes from residential complex, the growth rates of the sector are reflected in such indicators as foreign direct investment, employment and others.

If we compare Georgia's position at the regional level with neighboring countries, we will see that the share of the construction sector in GDP has been growing since 2010 despite some delays. (Figure 1). 


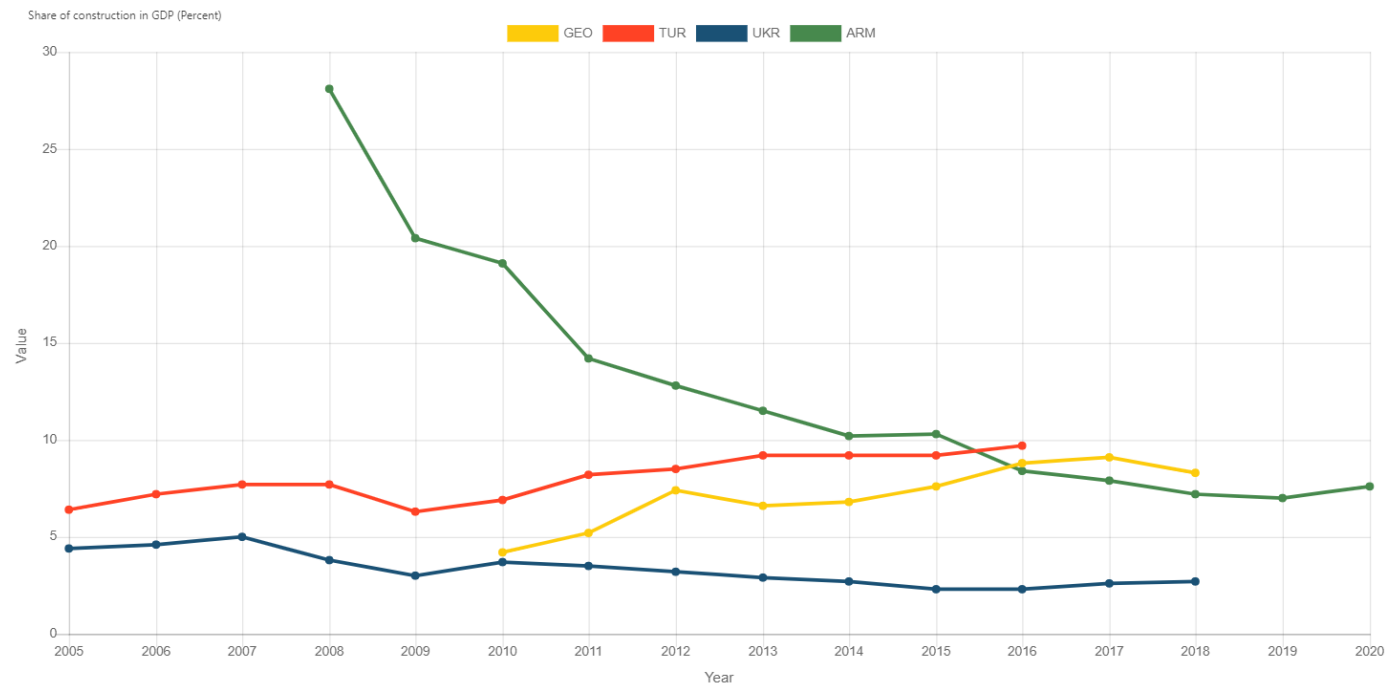

Fig. 1. The share of the construction sector in the country's Gross Domestic Product (GDP) in 20062020 (Georgia, Turkey, Ukraine, Armenia)

The importance of the sector is also determined by the fact that it has the ability to stimulate the local economy and can appear in the role of a consumer of local raw materials. In which, on the one hand it is the implementer of economic activity and at the same time leads to the development of neighbouring sectors and industries, all this creates a chain effect and serves the overall economic background of the country improvement. In addition, we know that the sector continues to provide socially vulnerable sections of the aging community and the workforce because it is less competitive in the labor market.

The importance of the sector in both direction is significant first as an important part of local production, as Georgia produces construction materials such as cement, brick, block, construction steel inert materials such as concrete inert composite large and small fillers, gravel and so on. It is important fact that in this respect the country dose not produce statistical material and accounting and construction materials are studied not only as an independent field but also as one of the parts of supply chain in the construction sector.

Exploring the potential of the building materials market is of interest to us as the construction sector is growing quite healthy and dynamic, according to this it has the potential to further promote the production of local building materials, it is also as an import category and in addition the overall construction cost.

The relevance of the construction materials market determines its contribution to the county's economy in attracting foreign direct investment, the price of construction materials is an important factor in the development of construction in the country, it can determine the intensity of infrastructure projects, affect all sectors and businesses, especially important in Georgia because for about 10 years after the collapse of the Soviet Union, the country experienced only a regression in this regard. In the 1990s, hundreds of factories, factories and administrative buildings were destroyed. The construction boom begins around 2006, when significant investment flows in this direction, so it can be said that the construction sector is still in the early stages of development and has not reached its peak of development, thus there is potential for growth in the construction products market or at least maintaining the current pace. And the growing number of constructions and the number of construction permits issued, which have not yet been completed, indicate the potential future demand for construction products, which means that there is a demand for construction products in the local market and it has the potential for growth.

Conclusions. After studying the issues raised in the paper and conducting research, we were able to answer the questions and draw conclusions: The construction sector in Georgia is growing and it will increase the consumption of construction products in the future.

Construction permits issued in the country and ease of obtaining a construction permit in general, despite other negative side effects, contribute to the development of the sector as a whole, thus affecting size of the construction materials market. 
The building materials market is also growing globally.

The global economic crisis has also affected the construction and building materials sector, with particular difficulties in restricting the timely transportation of labor and construction materials, although the sector has shown a growing trend since the removal of regulations.

The rapid exit of the sector from the pandemic was influenced by the state subsidy program which will finance mortage loans at $4 \%$ for five years.

The pandemic also affected the construction sector in Georgia, although for some companies operating in the construction sector, it ended with quite positive results as the sector continued to operate compared to other economic activities.

\section{REFERENCES}

1. G. Sulashvili, N. Pailodze, A. Abralava, R. Kutateladze, M. Sulashvili, I. Murvanidze, J. Gabaraevi, S. Kipiani. The Issues Regarding the Refinement of Effective Management of the Company. International Journal of Business and Economic Affairs (IJBEA) 2(3), 206-210. 2017, DOI: 10.24088/IJBEA-2017-23005 ISSN: 25199986. 206-210.

2. Retrieved from https://www.geostat.ge/ka/modules/categories/23/mtliani-shida-produkti-mshp

3. Retrieved from http://parliamnet.ge

4. Anzor Abralava, Rusudan Kutateladze, Nino Pailodze, Olga Khutsishvili, Giorgi Sulashvili, Alexander Kekenadze. The Causes of Economic Crisis and the Aspects of it's Development. Fifth Annual Conference of the Economic Forum of Entrepreneurship and International Business, ECO-ENA: Economics and EcoEngineering Associate, Harvard University, Boston, MA, USA, January 2015. Retrieved from www.eco-ena.ca

5. Ketevan Kokrashvili, Anzor Abralava, Rusudan Kutateladze, Nino Pailodze, Ketevan Kutateladze, Giorgi Sulashvili. Global Processes and Georgian Economic Policy. International Science Index Vol: 18. Dubai UAE, 18 (1) Part XXV. Jan 28-29, 2016

6. SIGMA, 2011, Public Procurement. Performance Measurement, Brief 21, Retrieved from http://www.sigmaweb.org/publications/Performance_Public_Procurement_2011.pdf.

7. World Economic Forum (WEF), 2016, The Global Competitiveness Report 2016-2017, Genewa, Retrieved from http://www3.weforum.org/docs/GCR2016-2017/05FullReport/TheGlobal Competitiveness Report2016-2017_FINAL.pdf

8. Edinburgh Group, 2015, Growing the Global Economy through SMEs; Retrieved from http://www.edinburghgroup.org/media/2776/edinburgh_group_research_-_growing_the_global_economy_through_smes.pdf. 